\title{
Effects of atorvastatin on some inflammatory markers in patients with multiple sclerosis treated by interferon beta-1b
}

\author{
Farah Waleed Mahmood*, Shamil Hashim Othman** \\ *Ibn-Siena Teaching Hospital, Nineveh Health Directorate, Ministry of Health ,Iraq. **Department of \\ pharmacology, College of Medicine, University of Mosul,Mosul, Iraq. Correspondence: \\ Shamil.othman@yahoo.com
}

$\begin{array}{ll}\text { Received } & \underline{\text { Accepted }} \\ 12.12 .2013 & 21.4 .2014\end{array}$

\begin{abstract}
Objective: To investigate the effect of Atorvastatin vs. placebo on some inflammatory markers in patients with multiple sclerosis treated by interferone beta1b.To achieve the aim of this study, a randomized control comparative trial was adopted.
\end{abstract}

Patients and Methods: A total of 100 patients with multiple sclerosis were recruited and investigated for some inflammatory markers which included, interleukin-2, tumor necrosis factor- $\alpha, \mathrm{C}$-reactive protein, and erythrocyte sedimentation rate. The patients were divided into 2 groups, namely the atorvastatin group which consisted of 50 patients and the placebo group which consisted of 50 patients. The patient groups were followed- up for 12 weeks during which the above parameters were measured before starting therapies and at the end of the follow-up period using commercially available kits. The patient groups were compared with the control group consisted of 50 apparently healthy subjects.

Results: The IL-2,TNF- $\alpha$, CRP and ESR at baseline in both patient groups were found significantly elevated as compared with the control group $(\mathrm{p}<0.001)$. The use of atorvastatinhas resulted in significant decrease on the above parameters with nonsignificant effects in the placebogroup. Atorvastatinappeared to be superior in compared with the placebo group.

Conclusion: The use of atorvastatinfor 12 weeks in patients withmultiple sclerosis treated by interferone-beta has beneficial effect on some inflammatory markers studied in this research( IL-2,TNF- $\alpha$, CRP and ESR).

Keywords: Multiple Sclerosis, Atorvastatin,Interferone-beta-1b. 


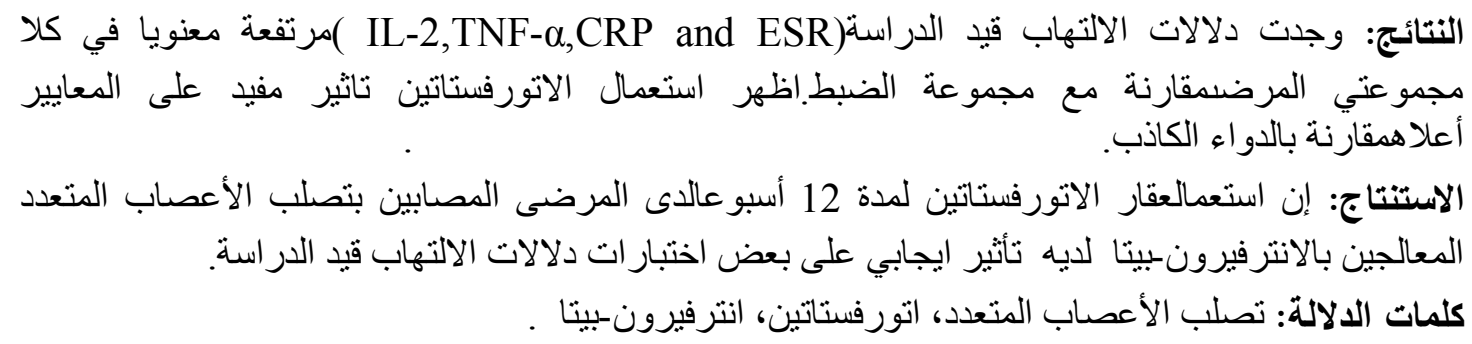

M ultiple sclerosis (MS) is an inflammatory autoimmune disorder invading myelin sheath in central nervous system $(\mathrm{CNS})^{1}$. It is the most common nontraumatic cause of disability in young adults, affecting approximately 2.5 million people worldwide; its prevalence is not uniform, with a latitudinal gradient of prevalence present in most studies ${ }^{2}$.

The etiology of MS is unknown. It likely results from complex interactions between environmental and genetic factors, which lead to an aberrant immune response and damage to the myelin sheath, oligodendrocytes, axons, and neurons $^{3}$. MS is considered to be an inflammatory autoimmune CD4 T-cell mediated disorder based on immune alterations in the blood and cerebrospinal fluid (CSF) as well as the pathological features in the brain ${ }^{4}$. Autoreactive activated T-cells invade the blood brain barrier and initiate an inflammatory response that leads to myelin destruction and significant neurological disability ${ }^{5}$.

Cytokines have crucial functions in the development, differentiation and regulation of immune cells. As a result, dysregulation of cytokine production or action is thought to have a central role in the development of autoimmunity and autoimmune diseases such as $\mathrm{MS}^{6}$. An imbalance in cytokines exists in MS, with the proinflammatory $\mathrm{T}$ helper1 (Th1) cytokines predominating over the anti- inflammatory and regulatory (Th2) cytokines ${ }^{7}$.This dysregulation in cytokine balance in individuals with MS is due to an increased Th1 immune response combined with a decreased Th2 response ${ }^{8}$.This imbalance is characterized predominately by increased levels of interferon gamma (IFN- $\gamma$ ), interleukin (IL)- 2 , interleukin (IL)- 12 and tumor necrosis factor alpha (TNF- $\alpha$ ) and decreased levels of IL-4, IL-10, and transforming growth factor-beta (TGF- $\beta)^{9}$.

In addition to this imbalance in cytokines, MS is characterized by increased levels of inflammatory markers which include serum soluble vascular adhesion molecule-1 (sVCAM-1), soluble intercellular adhesion molecule-1 (sICAM-1), Creactive protein (CRP), erythrocyte sedimentation rate (ESR), neopterin, serum nitric oxide metabolites nitrate and nitrite and alpha 1-acid glycoprotein (AGP) ${ }^{10}$.

Interferon-beta is an immunemodulatory drug that modulates T-cell activation and reduces inflammatory mediators and reduces the relapse rate in relapsing remitting $\mathrm{MS}^{11}$.

Experimental and clinical studies have demonstrated that statins can downregulate both acute and chronic inflammatory processes, reduce circulating CRP and proinflammatory cytokines levels ${ }^{12}$. These data suggest the potential value of statins in the treatment of $\mathrm{MS}^{13}$. Thus, the present study aims to:

1) compare the concentrations of some cytokines and inflammatory 
markers (IL-2, TNF- $\alpha$, CRP, and ESR) between MS patients and healthy individuals.

2) evaluate the effect of 3 month use of statin (atorvastatin) versus placebo on the concentrations of the above parameters in MS patients treated by interferon beta$1 b$.

\section{Patients and Methods}

The study was conducted in Ibn-Siena Consultation Clinic of Neurology, Mosul, Iraq. The subjects included in this study were selected over the six-month period of $1^{\text {st }}$ February to $1^{\text {st }}$ June 2013. To achieve the aim of the present study, a randomized control trial (RCT), openlabeled design was adopted.

Out of one-hundred twenty patients recruited in this study, only one-hundred patients whose ages mean \pm SD were $35.82 \pm 8.75$ years complaining from relapsing remitting multiple sclerosis (RRMS) in remission phase diagnosed according to McDonald criteria 2010 receiving subcutaneous interferon beta- $1 \mathrm{~b} 250$ $\mu \mathrm{g}$ every other day were completed the three months follow-up period.

The patients who were eligible to the study divided randomly into 2 equal groups. The first group consisted of fifty patients started to receive atorvastatin $20 \quad \mathrm{mg} \quad$ (Aditor) manufactured by Advanced Pharmaceutical Industries- Jordan twice daily in addition to their usual interferon beta-1btreatment. The second group consisted of fifty patients started to receive placebo capsules (glucose powder) twice daily in addition to their usual interferon beta$1 \mathrm{~b}$ treatment.

The study was approved by the ethical committee of Nineveh Health Directorate and all patients signed a written informed consent form. Fifty apparently healthy volunteers, matched for age, BMI and gender with the patients, were considered as a control group.

About $10 \mathrm{~mL}$ of venous blood was withdrawn, using a disposable syringe at about 8.00 to 10.00 am from the two MS patient groups and control subjects prior to start taking any drug (atorvastatin or placebo) and after three months of the drug use. $1 \mathrm{ml}$ of the blood was added to EDTA tube to calculate ESR. The remaining blood $(9 \mathrm{ml})$ allowed clotting in a plain tube at room temperature and then the serum was separated by centrifugation at $3000 \mathrm{rpm}$ for 10 minutes and kept frozen at $-20^{\circ} \mathrm{C}$ to be analyzed later on.

Determination of IL-2 and TNF- $\alpha$ concentrations was done using ELISA technique by commercially available kit.Serum CRP was measured by slide agglutination, using CRP Latex Test Kit.The recommended method for ESR measurement was Westergren method.

Statistical methods: Data are presented as mean \pm SD. Unpaired $\mathrm{t}$ test was used to compare between age and sex and inflammatory parameters of the control and those of the patients. Paired t-test was used to compare between the studied inflammatory parameters before and after therapy. Mann whitney test was used to compare the effect of atorvastatin vs placebo. Results considered significant at $p$ value equal or less than 0.05 .

\section{Results}

The characteristics of the patients and controls were presented in table 1 .

Table 2 shows that the serum levels of IL-2, TNF- $\alpha$, CRP and ESR were significantly higher $(p<0.01)$ in patients with MS allocated to interferon plus atorvastatin group before starting therapy as compared with the control group.By comparing the mean concentrations of IL-2, TNF$\alpha, \mathrm{CRP}$ and ESR in patients with MS before and after therapy, there was a 
significantdecrease $(p<0.01)$ in serum IL-2, TNF- $\alpha$, CRP and ESR levels after three months use of interferon plus atorvastatin.

Table 3 shows that the serum IL-2,TNF- $\alpha$, CRP and ESRlevels in patients with MS allocated to interferon plus placebo group were significantly higher $(p<0.01)$ before starting therapy as compared with the control subjects.By comparing the mean concentrations of IL-2,TNF- $\alpha$, ESR and CRPin patients with MS before and after therapy, there was no significant difference in the mean concentrations of IL-2,TNF- $\alpha$, ESRand CRPafter three months use of interferon plus placebo.

Table 4 illustrates the comparative effect of interferon plus atorvastatin and interferon plus placeboafter three months. Interferon plus atorvastatin appeared to produce more significant decrease $(p<0.01)$ for IL-2 , TNF- $\alpha$, ESR and CRP with regard to its effects on cytokines and the markers of inflammation as compared to Interferon plus placebo therapy

Table 1. Characteristics of multiple sclerosis patients and control group

\begin{tabular}{|c|c|c|c|c|}
\hline Parameters & $\begin{array}{l}\text { Controls } \\
\qquad n=50\end{array}$ & $\begin{array}{l}\text { Interferon } \\
\text { atorvastatin } \\
\qquad n=50\end{array}$ & $\begin{array}{l}\text { Interferon } \\
\text { placebo } \\
\qquad \mathrm{n}=50\end{array}$ & P-value \\
\hline Age(year) & $35.82 \pm 8.75$ & $35.30 \pm 8.62$ & $37.56 \pm 7.50$ & NS \\
\hline $\begin{array}{l}\text { Gender } \\
\text { Male } \\
\text { Female }\end{array}$ & $\begin{array}{l}16(32.0 \%) \\
34(68.0 \%)\end{array}$ & $\begin{array}{l}17(34.0 \%) \\
33(66.0 \%)\end{array}$ & $\begin{array}{l}10(20.0 \%) \\
40(80.0 \%)\end{array}$ & NS \\
\hline $\operatorname{BMI}\left(\mathrm{kg} / \mathrm{m}^{2}\right)$ & $25.44 \pm 3.63$ & $25.45 \pm 3.72$ & $26.23 \pm 3.93$ & NS \\
\hline
\end{tabular}

NS: Non significant difference from control group 
Table 2. Comparison of IL-2, TNF- $\alpha$, CRP and ESR among control andmultiple sclerosis patients on interferon plus atorvastatin (before and after) therapy.

\begin{tabular}{|l|c|c|c|}
\hline Parameters & \multicolumn{1}{|c|}{ Controls } & $\begin{array}{c}\text { Interferon }+ \\
\text { atorvastatin } \\
\text { before treatment } \\
\mathrm{n}=50\end{array}$ & $\begin{array}{c}\text { Interferon }+ \\
\text { atorvastatin } \\
\text { after treatment } \\
\mathrm{n}=50\end{array}$ \\
\hline IL-2 (ng/l) & $25.36 \pm 24.22$ & $722.89 \pm 230.04$ & $488.65 \pm 229.29$ \\
\hline TNF- $\alpha(\mathrm{ng} / \mathrm{l})$ & $23.11 \pm 11.66$ & $302.51 \pm 117.60$ & $144.79 \pm 122.55$ \\
\hline CRP $(\mathrm{mg} / \mathrm{l})$ & $7.20 \pm 3.20$ & $18.59 \pm 12.96$ & $6.24 \pm 1.18$ \\
\hline ESR $(\mathrm{mm} / \mathrm{H})$ & $11.70 \pm 6.00$ & $28.24 \pm 15.38$ & $11.88 \pm 9.92$ \\
& & & \\
\hline
\end{tabular}

a) $\mathrm{p}<0.01$ vs control

b) p $<0.01$ vsinterferon + atorvastatinafter treatment

Table 3. Comparison of IL-2,TNF- $\alpha$, CRP and ESR betweencontrol \&multiple sclerosis patients on interferon plus placebo (before and after) therapy.

\begin{tabular}{|l|l|c|c|}
\hline Parameters & \multicolumn{1}{|c|}{ Controls } & $\begin{array}{c}\text { Interferon }+ \\
\text { placebo } \\
\text { before treatment } \\
\mathrm{n}=50\end{array}$ & $\begin{array}{c}\text { Interferon }+ \\
\text { placebo } \\
\text { after treatment } \\
\mathrm{n}=50\end{array}$ \\
\hline IL-2 (ng/l) & $25.36 \pm 24.22$ & $725.02 \pm 201.11^{*}$ & $722.14 \pm 199.27$ \\
\hline $\begin{array}{l}\mathrm{TNF}-\alpha \\
(\mathrm{ng} / \mathrm{l})\end{array}$ & $23.11 \pm 11.66$ & $405.75 \pm 131.15^{*}$ & $402.63 \pm 134.33$ \\
\hline $\begin{array}{l}\mathrm{CRP}(\mathrm{mg} / \mathrm{l}) \\
\mathrm{E}\end{array}$ & $7.20 \pm 3.20$ & $12.84 \pm 15.38^{*}$ & $13.20 \pm 15.42$ \\
\hline $\begin{array}{l}\mathrm{ESR} \\
(\mathrm{mm} / \mathrm{H})\end{array}$ & $11.70 \pm 6.00$ & $31.22 \pm 12.22^{*}$ & $31.32 \pm 11.68$ \\
\hline
\end{tabular}


Table 4. Difference of percentage variation between multiple sclerosis patients on interferon plus atorvastatin and interferon plus placebo therapies.

\begin{tabular}{|l|l|l|l|}
\cline { 2 - 4 } \multicolumn{1}{|c|}{ Parameters } & \multicolumn{1}{|c|}{$\begin{array}{c}\text { Interferon }+ \\
\text { atorvastatin } \\
\mathrm{n}=50\end{array}$} & $\begin{array}{c}\text { Interferon }+ \\
\text { placebo } \\
\mathrm{n}=50\end{array}$ & P-value \\
\hline IL-2 (ng/l) & $-231.89 \pm 181.61$ & $-2.87 \pm 21.88$ & $<0.01^{*}$ \\
\hline TNF- $\alpha(\mathrm{ng} / \mathrm{l})$ & $-157.72 \pm 136.75$ & $-3.12 \pm 14.77$ & $<0.01^{*}$ \\
\hline CRP (mg/l) & $-6.72 \pm 17.84$ & $0.36 \pm 3.29$ & $<0.01^{*}$ \\
\hline ESR (mm/H) & $-16.36 \pm 10.98$ & $0.10 \pm 4.46$ & $<0.01^{*}$ \\
\hline
\end{tabular}

*Significant differences using Mann Whitney test

\section{Discussion}

The current study was performed to assess the level of some Th1 cytokines and inflammatory markers in MS patients and to test whether atorvastatinuse can reduce these markers. The two MS groups and control group participate in this study were tested statistically for the absence of significant differences between the studied groups in concerning age, gender and body mass index (BMI) to exclude any effect of these parameters on the results of the study.

In this study, serum concentrations of IL- 2 and TNF- $\alpha$ were found significantly higher in patients with MS in both drug groups than the control subjects. This is not surprising as pro-inflammatory cytokines such as IL-1, TNF- $\alpha$, IL-2, IFN- $\gamma$ are believed to contribute to the tissue injury in MS, while anti-inflammatory cytokines produced by Th2 cells (IL-4, IL-10) have been shown to down regulate the immune response ${ }^{14}$; and the results of the current study were in agreement with a previous study published in $2010^{15}$. Despite clinically inactive disease and immunomodulator therapy, higher TNF- $\alpha$ and IL-2 of the patients suggested a continuous subclinical immune activity that could not be suppressed by treatment ${ }^{16}$.

C-reactive protein is a generalized marker for inflammation, and elevated serum levels of CRP have been extensively studied in relation to cardio pathology. However, elevated levels of CRP have more recently been linked to CNS pathologies characterized by CNS inflammation including Alzheimer's disease and Parkinson's disease; this suggests that CRP may also play a role in modulating MS ${ }^{17}$. Actually many investigators have used CRP as an inflammatory marker in assessing inflammation in MS patients ${ }^{18,19}$. In this study, CRP was found higher than the control and this was in agreement with a previous study of 30 RRMS patients on interferon beta in whomCRP levels were higher than the control subjects ${ }^{20}$. Conversely the current result disagreed with a study published in 2011 which did not report any difference in CRP level between MS and control group ${ }^{21}$.

The current study found that ESR level in MS patients was higher than control subjects. One previous 
study demonstrated that ESR may be moderately elevated in MS patients ${ }^{22}$; another study reported that ESR increased during relapses, and became significantly lower after intravenous glucocorticoid treatment ${ }^{23}$. While, and in contrast to our result, another study did not found any differencesin ESR between MS patients and healthy subjects $^{24}$.

Because of their immunomodulatory properties, statins are currently under investigation as treatment for MS. This concept was first tested in 1999 by Stanislaus et al., who showed that lovastatin reduced mononuclear-cell infiltration into the brain and attenuated the clinical signs of experimental autoimmune encephalomyelitis (EAE), the animal model of multiple sclerosis ${ }^{25}$. The attenuation of EAE by statins was attributed to the up-regulation of Th2 cytokines such as IL-4, IL-10 and transforming growth factor-b1 (TGF$\mathrm{b} 1)^{26}$. Statins improve proliferation and survival of oligodendrocyte precursors in vitro and improve myelination in vivo $^{27}$. Oral atorvastatin was shown to prevent or reverse chronic or relapsing paralysis due to demyelination in a murine model. This was associated with a shift from Th-1type immune responsetowards $\mathrm{Th}-2$ type responses in vivo. These results suggest a possible role of statins in inflammatory phase of MS and other Th-1 mediated autoimmune diseases including diabetes and rheumatoidarthritis ${ }^{28}$.

Current study found that three months use of atorvastatin produced beneficial effect in MS patientsthrough significant decrease in IL-2, TNF- $\alpha$, CRP and ESR.These results are in agreement with a previous study reported that simvastatin has shown to increase IFN- $\gamma$, IL-12 and IL-4 expression and to decrease TNF- $\alpha$ and IL-10 in $\mathrm{T}$ cells in vitro ${ }^{29}$. Another study found that mean levels of two
Th2 cytokine (IL-4 and IL-10) increased after addition of atorvastatin to interferon-beta- $1 \mathrm{~b}$; but failed to reach statistical significance ${ }^{30}$.In contrast to this, aplacebo-controlled randomized trialfound non-significant difference between simvastatin and placebo group at 12 months duration and concluded that there is no beneficial effect of simvastatin $80 \mathrm{mg}$ as add-on therapy to interferon beta$1 \mathrm{a}^{31}$. Another study also concluded that atorvastatin $40 \mathrm{mg} /$ day added to interferon beta-1b did not have a beneficial effect on relapsing-remitting MS compared to interferon beta- $1 \mathrm{~b}$ monotherapy over a 12-month period $^{32}$.

In conclusion, the addition of atorvastatinfor three months to interferon beta- $1 \mathrm{~b}$ treatment has $\mathrm{a}$ beneficial effects on markers of disease activity such asIL-2,TNF- $\alpha$, ESR and CRP in patients with MS.

\section{References}

1. Fatehi F, Shaygannejad V, Mehr L, et al. Optical coherence tomography versus visual evoked potential in multiple sclerosis patients.Ir $\mathrm{J}$ neurol 2012;11:12- 15.

2. Taylor BV, Pearson JF, Clarke G, et al. MS prevalence in New Zealand, an ethnically and latitudinally diverse country. MultScler 2010;16:14221431.

3. Tullman MJ. Overview of the epidemiology, diagnosis, and disease progression associated with multiple sclerosis.Am J Manag Care 2013;19:15-20.

4. Greenstein JI. Current concepts of the cellular and molecular pathophysiology of multiple sclerosis. Develop Neurobiol 2007;67:12481265.

5. Achiron A, Gurevich M, Magalashvili D, et al. Understanding autoimmune mechanisms in multiple sclerosis using gene expression 
microarrays. Clin DevImmunol 2004; 11:299-305.

6. Dhib-Jalbut S. Mechanisms of action of interferons and glatiramer acetate in multiple sclerosis. Neurology 2002;58:3-9.

7. Alexander JS, Harris MK, Wells $\mathrm{SR}$, et al. Alterations in serum MMP-8, MMP-9, IL-12p40 and IL-23 in multiple sclerosis patients treated with interferon-beta1b. MultScler 2010; 16:801-809.

8. Zhang GX, Baker CM, Kolson DL et al. Chemokines and chemokine receptors in the pathogenesis of multiple sclerosis. MultScler 2000; 6:3-13.

9. Clerici M, Saresella M, Trabattoni D, et al. Single-cell analysis of cytokine production shows different immune profiles in multiple sclerosis patients with active or quiescent disease.J Neuroimmunol 2001;121:88101.

10. Weinstock-Guttman B, Baier $M$, Park Y, et al. Low fat dietary intervention with omega-3 fatty acid supplementation in multiple sclerosis patients. Prostaglandins LeukotEssent Fatty Acids 2005;73:397-404.

11. Holmoy $T$, Vartdal $F$. The immunological basis for treatment of multiple sclerosis. Scand J Immunol 2007;66:374-382.

12. Lefer DJ. Statins as potent antiinflammatory drugs. Circulation 2002;106:2041-2042.

13. Paul F, Waiczies $S$, Wuerfel J, et al. Oral high-dose atorvastatin treatment in relapsing-remitting multiple sclerosis. PLOS ONE 2008; 3(4):e1928.

14. Imitola $J$, Chitnis $T$, Khoury SJ. Cytokines in multiple sclerosis: from bench to bedside. Pharmacol Ther 2005;106:163-77.

15. Tasdemir N, Karaca EE, Ece A, et al. Multiple sclerosis: Relationships between cytokines, MRI lesion burden, visual evoked potentials and disability scores. Eur J Gen Med 2010;7:167173.

16. Burns SA, Archer RL, Chavis JA, et al. Mitoxantrone repression of astrocyte activation: Relevance to multiple sclerosis.Brain Res 2012; 1473:236-241.

17. Coric J, Pasic A, Panjeta M, et al. Evaluation of high sensitivity Creactive protein assay in cerebrospinal fluid on the Dimension RxL analyzer. J Heal Sci 2012;21:13-16.

18. Sellner J, Greeve I andMattle HP. Atorvastatin decreases high sensitivity C-reactive protein in multiple sclerosis.MultScler2008;14:981-984.

19. Hon GM, Hassan MS, Rensburg $\mathrm{SJ}$, et al. Immune cell membrane fatty acids and inflammatory marker, Creactive protein in patients with multiple sclerosis. Br J Nutr 2009; 19:1-7.

20. Palavra F, Marado D, Mascarenhas-Melo F, et al. New markers of early cardiovascular risk in multiple sclerosis patients: OxidizedLDL correlates with clinical staging. Dis Markers 2013;34:341-348.

21. Fjeldstad AS, McDaniel J, Witman MA, et al. Vascular function and multiple sclerosis. J Neuro 2011; 258:2036-2042.

22. Scolding N. The differential diagnosis of multiple sclerosis.J NeurolNeurosurg Psychiatry 2001; 71:9-15.

23. Glass-Marmor L, Paperna $T$, Galboiz Y, et al. Immunomodulation by chronobiologically- based glucocorticoids treatment for multiple sclerosis relapses. J Neuroimmunol 2009;210:124-127.

24. Aksungar FB, Topkaya AE, Yildiz $Z$, et al. Coagulation status and biochemical and inflammatory markers in multiple sclerosis. J Clin Neurosci 2008;15:393-397.

25. Stanislaus R, Pahan $K$, Singh AK, et al. Amelioration of experimental allergic encephalomyelitis in Lewis 
rats by lovastatin. Neurosci Lett 1999;269:71-74.

26. Paintlia AS, Paintlia MK, Singh $\mathrm{AK}$, et al. Regulation of gene expression associated with acute experimental autoimmune encephalomyelitis by lovastatin. J Neurosci Res 2004;77:63-81.

27. Paintlia AS, Paintlia MK, Khan M et al. HMG-CoA reductase inhibitor augments survival and differentiation of oligodendrocyte progenitors in animal model of multiple sclerosis. FASEB J 2005;19:1407-1421.

28. Yonssef S, Stuve O, Patarroyo JC, et al. The HMG-CoA reductase inhibitor, atorvastatin, promotes a Th2 bias and reverses paralysis in central nervous system autoimmune disease. Nature 2002;420:78-84.

29. NeuhausO, Strasser-Fuchs $\mathrm{S}$, Fazekas F, et al. Statins as immunomodulators: comparison with interferon-beta $1 \mathrm{~b}$ in MS. Neurology 2002;59:990-997.

30. Sellner J, Greeve I, Findling O, et al. Effect of interferon-beta and atorvastatin on Th1/Th2 cytokines in multiple sclerosis. NeurochemInt 2008;53:17-21.

31. Sorensen PS, Lycke J, Eralinna JP, et al. Simvastatin as add-on therapy to interferon $\beta$-1a for relapsing-remitting multiple sclerosis (SIMCOMBIN study): a placebo-controlled randomised phase 4 trial. Lancet Neurol 2011;10:691-701.

32. Kamm CP, El-Koussy $M$, Humpert S, et al. Atorvastatin added to interferon $\beta$ for relapsing multiple sclerosis: a randomized controlled trial. J Neurol 2012;259: 2401-2413. 